\title{
Modelling of Unbonded Post-Tensioned Concrete Slabs Under Fire Conditions
}

DOI:

10.1016/j.firesaf.2008.05.007

Link to publication record in Manchester Research Explorer

\section{Citation for published version (APA):}

Bailey, C., \& Ellobody, E. (2009). Modelling of Unbonded Post-Tensioned Concrete Slabs Under Fire Conditions. Fire Safety Journal, 44(2), 159-167. https://doi.org/10.1016/j.firesaf.2008.05.007

\section{Published in:}

Fire Safety Journal

\section{Citing this paper}

Please note that where the full-text provided on Manchester Research Explorer is the Author Accepted Manuscript or Proof version this may differ from the final Published version. If citing, it is advised that you check and use the publisher's definitive version.

\section{General rights}

Copyright and moral rights for the publications made accessible in the Research Explorer are retained by the authors and/or other copyright owners and it is a condition of accessing publications that users recognise and abide by the legal requirements associated with these rights.

\section{Takedown policy}

If you believe that this document breaches copyright please refer to the University of Manchester's Takedown Procedures [http://man.ac.uk/04Y6Bo] or contact uml.scholarlycommunications@manchester.ac.uk providing relevant details, so we can investigate your claim.

\section{OPEN ACCESS}




\title{
Modelling of unbonded post-tensioned concrete slabs under fire conditions
}

\author{
Ehab Ellobody ${ }^{\mathrm{a}}$, Colin G. Bailey ${ }^{\mathrm{b}, *}$ \\ a Department of Structural Engineering, Faculty of Engineering, Tanta University, Tanta, Egypt \\ b School of Mechanical, Aerospace and Civil Engineering, The University of Manchester, Pariser Building, PO Box 88, Sackville Street, M60 1QD Manchester, UK
}

\section{A R T I C L E I N F O}

\section{Article history:}

Received 7 February 2008

Received in revised form

9 May 2008

Accepted 11 May 2008

Available online 24 June 2008

Keywords:

Finite element modelling

Fire

Post-tensioned concrete slabs

Structural design

Tendon

Unbonded

\begin{abstract}
A B S T R A C T
This paper investigates the structural behaviour of unbonded post-tensioned one-way spanning concrete slabs in fire conditions. The slabs were simply supported and reinforced with $15.7 \mathrm{~mm}$ nominal diameter seven-wire mono-strand tendons. A nonlinear finite element model for the analysis of posttensioned unbonded concrete slabs at elevated temperatures was developed. The mechanical and thermal material nonlinearities of the concrete, prestressing tendon and anchorages have been carefully inserted into the model. The interface between the tendon and surrounding concrete was also modelled, allowing the tendon to retain its profile shape during the deformation of the slab. The temperature distribution throughout the slab, time-deflection behaviour, time-longitudinal expansion, time-stress behaviour in the tendon, and the failure modes were predicted by the model and verified against test data. The study has shown that the coefficients of thermal expansion currently used in the European Code for calcareous and siliceous concrete can lead to inaccurate predictions of the structural behaviour. A parametric study was conducted to investigate the effects on the global structural behaviour due to the change in the aggregate type, load ratio and boundary conditions. It was shown that by varying the boundary conditions the fire resistance was greatly affected. Although changing the aggregate type and load ratio affected the time-displacement response, the fire resistance defined by failure of the slab was not affected due to the splitting mode of failure above the tendon locations not being affected by these parameters. Comparison with the codes shows that the UK code BS8110 is generally unconservative, whereas the Eurocode EN1992-1-2 provides reasonable design rules.
\end{abstract}

(c) 2008 Elsevier Ltd. All rights reserved.

\section{Introduction}

Although post-tensioned concrete slabs have many advantages including readily achievable clear spans, small construction depths and rapid construction, the performance of the slabs in fire conditions is still not fully understood. Post-tensioning of concrete slabs can be constructed using unbonded or bonded tendons. For unbonded slabs the transfer of force from the tendons to the concrete is via the end anchors, with strains in the tendons distributed throughout their entire length, and also via the profile of the tendons. Friction forces between the tendon and concrete are very small since the tendon is typically greased and housed within a plastic tube. In bonded slabs the transfer of the force is via the end anchors, the bond between the tendons and concrete, and the curvature of the tendons.

Currently there is very limited test data highlighting the behaviour of unbonded post-tensioned concrete slabs at elevated temperatures. Previous tests comprise three standard fire tests

\footnotetext{
* Corresponding author. Tel.: +44161306 5795; fax: +441613064646.

E-mail address: Colin.Bailey@manchester.ac.uk (C.G. Bailey).
}

[1,2] carried out in the 1950 and 1960s on restrained unbonded post-tensioned concrete slabs, based on the form of construction relevant at the time, in the USA. In addition, Herberghen and Damme [3] carried out nine tests on unbonded slab strips and reached the conclusion that additional untensioned (passive) reinforcement should be added to the slabs to avoid premature failure under fire conditions. Observations from real fires in buildings with unbonded slabs have highlighted various responses. Lukkunaprasit [4] has presented a review of a fire in an 18-storey office block in Bangkok where partial collapse of the floor occurred, which was attributed to severe spalling exposing the tendons. Whereas Troxell [5] and Sarkkinen [6] both presented reviews of real fires, one in a two-storey school and one in a fivestorey building under construction, where the post-tensioned floor slab withstood the fire without any signs of collapse. A detailed review of these previous tests and observations from real fires has been provided by Lee and Bailey [7].

Recently, Bailey and Ellobody [8] conducted a series of tests on unbonded post-tensioned one-way concrete slabs in fire conditions. Four slabs were subjected to a fire under a static load equal to $50 \%$ of their capacity in the cold condition. The tests highlighted the different structural response between using Limestone and 


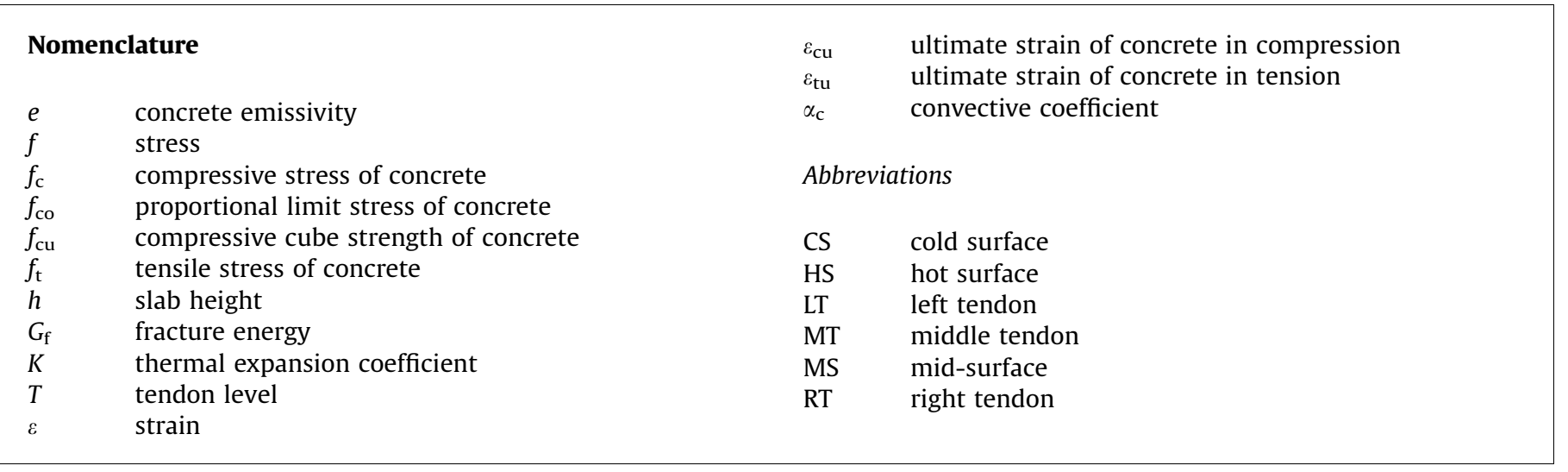

Thames Gravel (TG) aggregates and different longitudinal restraint conditions. The temperature distribution through the slabs, the strains in the tendons and the horizontal and vertical displacements were measured in each test. The tests have shown that slabs with TG aggregates have a much higher deflection compared to slabs with Limestone aggregates, and the restrained slabs had lower vertical deflection compared to equivalent unrestrained slabs. Cracks directly above and parallel to the tendons were observed in all the fire tests.

Once validated, the use of finite element modelling can provide a detailed insight into the behaviour of concrete structural members in fire. Numerous finite element models have been developed to study the behaviour of concrete structural members in fire conditions, such as those presented by Hosser et al. [9] Bailey et al. [10], Izzuddin [11], Song et al. [12], Elghazouli and Izzudin [13], Gillie et al. [14], Lim et al. [15] and Zhang and Bradford [16]. However, numerical models investigating the behaviour of posttensioned concrete slabs in fire have not been adequately developed to date, with some progress presented by Lee and Bailey [7] and Ellobody and Bailey [17]. The main objective of this paper is to provide a better understanding for the behaviour of post-tensioned unbonded one-way spanning concrete slabs in fire conditions through numerical investigation. An efficient nonlinear 3-D finite element model was developed using ABAQUS [18] and verified against the tests conducted by Bailey and Ellobody [8]. A parametric study has been conducted to study the effects of the change in the aggregate type, load ratio and boundary conditions on the behaviour of unbonded post-tensioned one-way concrete slabs at elevated temperatures. The results of the numerical investigation have been compared with the design values specified in BS 8110-2 [19], and BSEN 1992-1-2 [20], with conclusions being drawn.

\section{Summary of experimental investigation}

As shown in Table 1, six tests-two at ambient temperature [21] and four at elevated temperature [8]-were carried out on

Table 1

Tests on unbonded post-tensioned concrete slabs

\begin{tabular}{lllllll}
\hline Test specimen & Fire & \multicolumn{2}{l}{ Thermal expansion } & & \multicolumn{2}{l}{ Coarse aggregate } \\
\cline { 5 - 6 } \cline { 5 - 6 } & & Free & Restrained & & Limestone & Thames Gravel \\
\hline T1 & & $\mathrm{X}$ & & $\mathrm{X}$ & \\
T2 & & $\mathrm{X}$ & & & $\mathrm{X}$ \\
T3 & $\mathrm{X}$ & $\mathrm{X}$ & & $\mathrm{X}$ & \\
T4 & $\mathrm{X}$ & & $\mathrm{X}$ & & $\mathrm{X}$ & $\mathrm{X}$ \\
T5 & $\mathrm{X}$ & $\mathrm{X}$ & & & $\mathrm{X}$ \\
T6 & $\mathrm{X}$ & & $\mathrm{X}$ & & \\
\end{tabular}

unbonded post-tensioned slabs. The slabs were designed according to BS 8110-1 [22] and the Concrete Society Technical Report 43 [23]. The slabs were $4.3 \mathrm{~m}$ long, $1.6 \mathrm{~m}$ wide, and $160 \mathrm{~mm}$ deep. Each slab had three longitudinal parabolic tendons with a nominal diameter of $15.7 \mathrm{~mm}$ and an area of $150 \mathrm{~mm}^{2}$. One tendon was positioned in the middle of the slab with the other two positioned either side, at a spacing of $530 \mathrm{~mm}$, as shown in Fig. 1. The tendon was a mono-strand with seven high-strength steel wires, with an average measured tensile strength of $1846 \mathrm{MPa}$. The tendon was greased and housed in a thin polypropylene extrusion sleeve, which had been moulded directly onto the strand. Each tendon was supported on seven steel chairs to maintain the designed curvature of the tendon. Each tendon passed through the dead and live anchorages which were placed at mid-height at the ends of the slab. The distance from the bottom of the slab to the centre of the tendon, at the mid-span of the slab, was $42 \mathrm{~mm}$. Bursting reinforcement was designed according to BS8110-1 [22] to resist tensile bursting forces around individual anchorages. No other non-tensioned reinforcement was included. The concrete cube strength at 4,14 and 28 days after casting, as well as at the time of testing, is shown in Table 2, together with the measured moisture content for the slabs tested under fire conditions.

The full applied design prestressing force to the slabs was $195 \mathrm{kN}$, with the average measured force in the three tendons being $169 \mathrm{kN}$, equating to $13 \%$ losses. Further details of the posttensioned process, and measurements obtained during this process, are presented in [21].

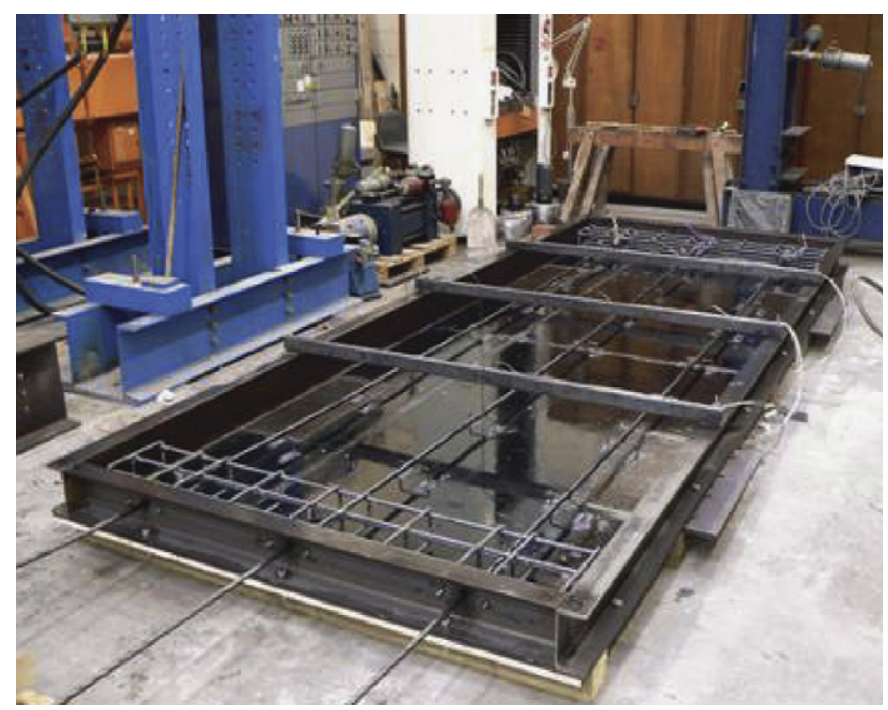

Fig. 1. Mould used for casting the test specimens. 
Table 2

Measured concrete cube strengths at ambient temperature

\begin{tabular}{|c|c|c|c|c|c|c|}
\hline \multirow[t]{2}{*}{ Slab } & \multirow[t]{2}{*}{ Aggregate type } & \multicolumn{4}{|c|}{ Measured concrete strength at different days after casting (MPa) } & \multirow[t]{2}{*}{ Moisture content (\%) } \\
\hline & & 4 days & 14 days & 28 days & At testing & \\
\hline T1 & Limestone & 30.8 & 40.7 & 42.7 & 44.4 & - \\
\hline $\mathrm{T} 2$ & Thames gravel & 35.0 & 43.7 & 45.8 & 48.2 & - \\
\hline T3 & Limestone & 36.3 & 42.0 & 44.9 & 48.0 & 2.54 \\
\hline $\mathrm{T} 4$ & Limestone & 30.8 & 36.2 & 41.6 & 41.0 & 2.15 \\
\hline T5 & Thames gravel & 31.6 & 37.3 & 40.3 & 40.0 & 2.34 \\
\hline T6 & Thames gravel & 30.2 & 36.8 & 38.1 & 39.7 & 1.70 \\
\hline
\end{tabular}
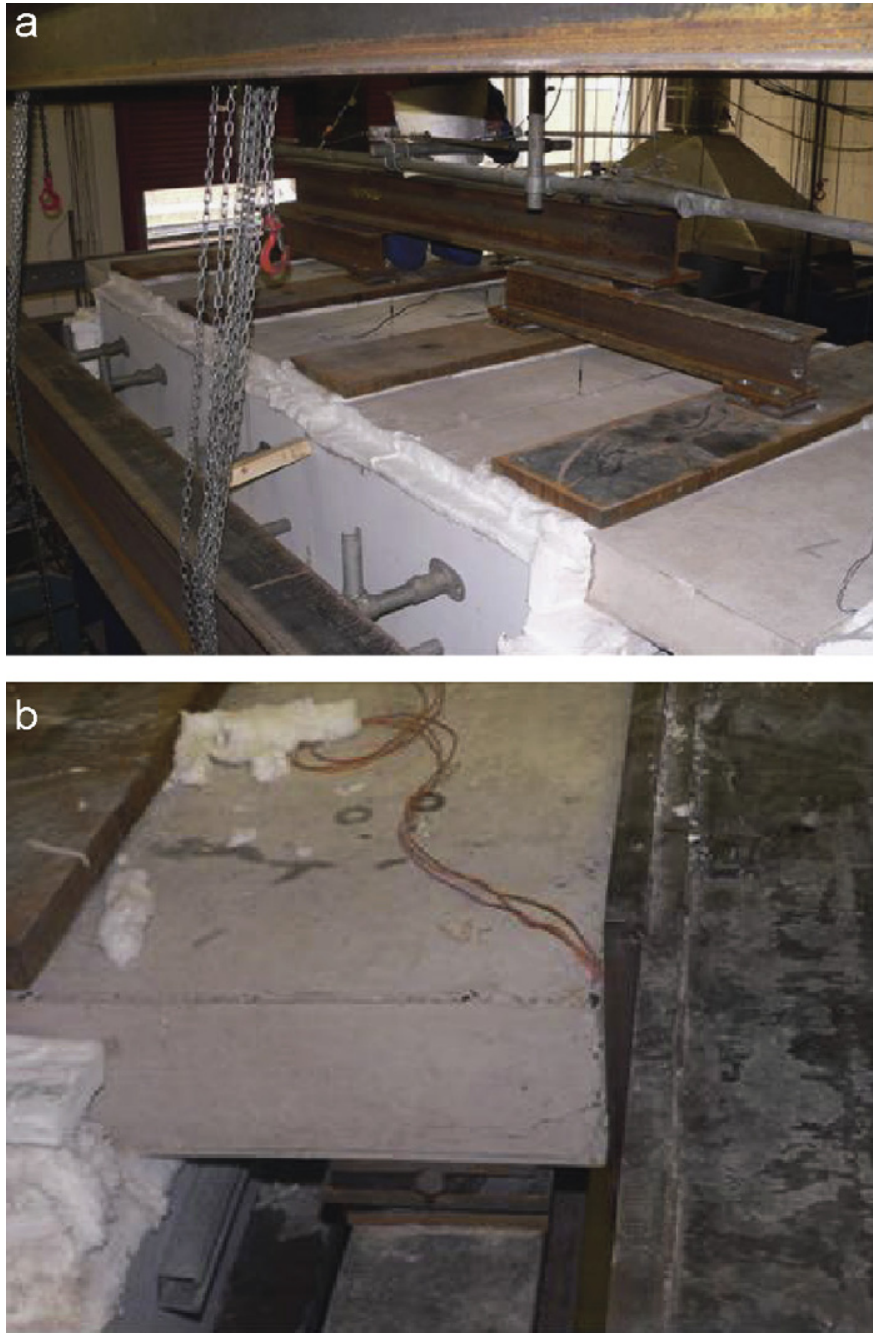

Fig. 2. Test setup: (a) loading tree and (b) longitudinal restraints.

The slabs were tested over a span of $4.0 \mathrm{~m}$. In the ambient tests, the slabs were loaded to failure, while in the fire tests the slabs were subjected to a static load equal to $50 \%$ of the capacity of Slab $\mathrm{T} 1(156.6 \mathrm{kN})$ in the cold condition. The slabs were loaded at four locations using spreader plates $1600 \times 350 \times 40 \mathrm{~mm}$, as shown in Fig. 2(a). The applied load, the strains in the tendons and the vertical deflections were measured in all the tests. In the fire tests, temperatures through the slab were also measured together with horizontal longitudinal displacements in the unrestrained slabs, with the middle $3.2 \mathrm{~m}$ of the slab heated. The strains in the tendons were measured near the ends of the tendons ensuring that gauges remained at ambient temperature. Since the tendons were unbonded these gauges should give a good indication of the strains within the tendons. The slabs were heated in the fire tests using two burners with the aim of following the standard time-temperature curve specified in BSEN1991-1-2 [24]. Further details of the tests and results obtained are given in Refs. [8] and [21] for the fire and ambient tests, respectively.

In the restrained fire tests, two restraining beams were designed and positioned against both ends of the slab to prevent horizontal displacement and end rotation of the slab, as shown in Fig. 2(b). The beams were bolted to the loading frame, which allowed initial slight expansion to occur until the slab became in full contact with the restraining beams and until the bolts fixing the restrained beams were in contact with the edges of the holes. Further details for the test setup of the restrained fire tests are given in Ref. [8].

\section{Finite element model}

A combination of 3-D solid elements (C3D8 and C3D6) available within ABAQUS [18] was used to model the concrete, tendon and anchorage elements. The elements have three degrees of freedom per node. Due to symmetry, only one-quarter of the slab was modelled (Fig. 3), with 6414 elements, including the interface elements, used. The boundary conditions and load application were identical to that used in the tests. The measured post-tensioning stress in the tendons $(169 \mathrm{kN})$ was initially applied in a separate step. The dead load representing the weight of the slab was applied as a static uniformly distributed load on the top surface of the slab and the dead load representing the weight of the loading tree (Fig. 2a) was applied as a static distributed load over the area of the spreader plates. For the ambient tests the jack load was applied in increments as a static distributed load over the area of the spreader plates. For the fire tests the applied load remained constant and the temperature within the slab increased.

For the modelling of the fire tests a thermal analysis was conducted, using the *HEAT TRNSFER option available within ABAQUS [18], to evaluate the temperature distribution throughout the slabs, based on the measured furnace curve from the test. A constant convective coefficient $\left(\alpha_{c}\right)$ of $25 \mathrm{w} / \mathrm{m}^{2} \mathrm{k}$ was assumed for the exposed surface and $9 \mathrm{w} / \mathrm{m}^{2} \mathrm{k}$ was assumed for the unexposed surface. The radiative heat flux was calculated using a concrete emissivity $(e)$ value of 0.7 .

Concrete was modelled using the damaged plasticity model implemented within ABAQUS [18]. Under uniaxial compression the response is linear until the value of the proportional limit stress, $\left(f_{\text {co }}\right)$ is reached, which is assumed to equal 0.33 times the compressive strength $\left(f_{\mathrm{c}}\right)$, as shown in Fig. 4a. Under uniaxial tension the stress-strain response follows a linear elastic relationship until the value of the failure stress. The tensile failure stress is taken as 0.1 times the compressive strength of concrete $f_{c}$, which is assumed to be equal to 0.67 times the measured concrete cube strength $\left(f_{\mathrm{cu}}\right)$. The softening stress-strain response, past the 


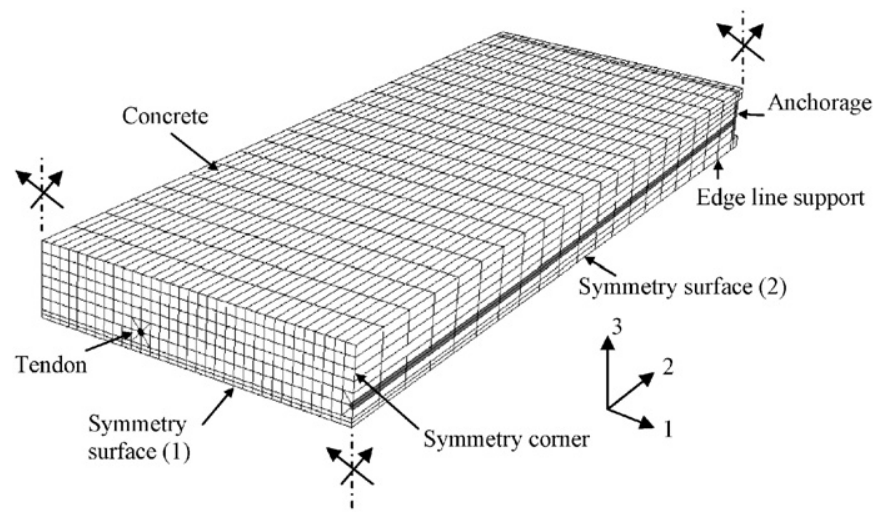

Fig. 3. Finite element mesh for quarter of the slab.

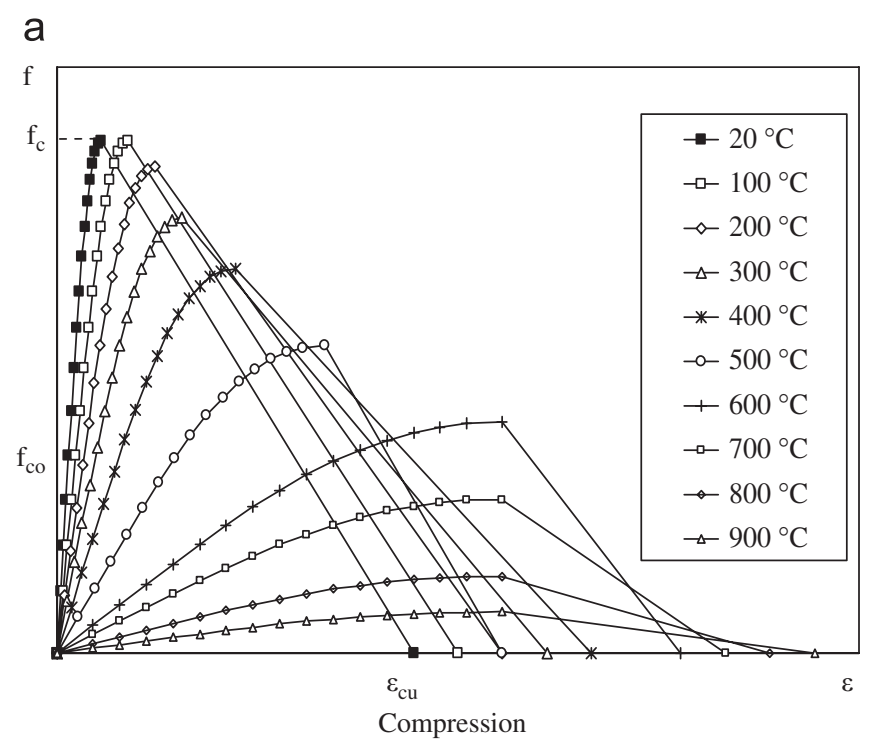

b

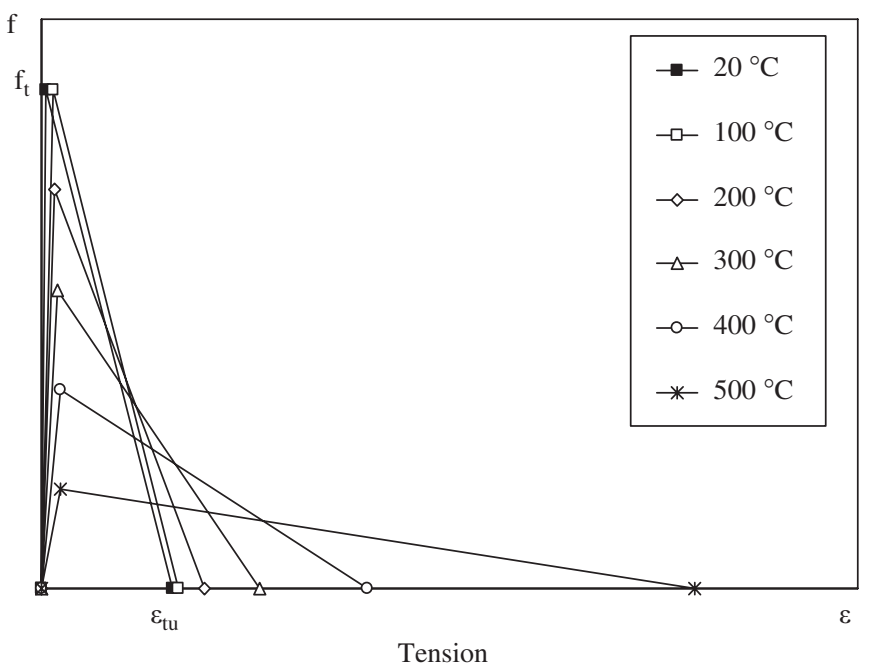

Fig. 4. Stress-strain curves of concrete at elevated temperatures.

maximum tensile stress, was represented by a linear line defined by the fracture energy and crack bandwidth. The fracture energy $G_{\mathrm{f}}$ (energy required to open a unit area of crack) was taken as $0.217 \mathrm{~N} / \mathrm{mm}$. The fracture energy divided by the crack bandwidth was used to define the area under the softening branch of the tension part of the stress-strain curve, as shown in Fig. 4b. The crack bandwidth was assumed as the cubic root of the volume between integration points for a solid element, as recommended by CEB [25]. The measured stress-strain curve of the tendon at ambient temperature, as shown in Fig. 5, was used in modelling the tendons. The contact between the concrete and the tendon was modelled by interface elements (using the *CONTACT PAIR option) available within the ABAQUS [18] element library. The interface elements consisted of two matching contact faces from the tendon elements and surrounding concrete elements. No friction between the two faces was modelled to represent unbonded tendons. The interface element allowed the surfaces to displace relative to each other but ensured that the contact elements could not penetrate each other.

The stress-strain-temperature curves for concrete in compression and tension are shown in Fig. 4. The curves were based on the reduction factors given in BSEN1992-1-2 [20] for calcareous aggregate, which were adopted for the Limestone aggregate used in this study, and siliceous aggregate, which were adopted for the TG used in this study. The specific heat and thermal conductivity were also calculated according to BSEN1992-1-2 [20], with the measured moisture content considered in the calculation of the specific heat of concrete. The measured stress-strain curve for the tendon at ambient temperature was used to calculate the stress-strain curves at elevated temperatures following the reduction factors given in BSEN1992-1-2 [20], as shown in Fig. 5. Similar curves were used for the anchorages with material properties at ambient temperature conforming to BS 4447 [26].

The thermal-mechanical analysis is very sensitive to the coefficient of thermal expansion used [27]. In the absence of measured values, the coefficients of thermal expansion are typically calculated based on data available in design codes, for siliceous and calcareous aggregates. Since one of the main objectives of this study is to investigate the effect of the coarse aggregate type on the performance of post-tensioned concrete slabs in fire, proposed thermal expansion coefficients for concrete with Limestone and TG aggregates were also introduced based on measured values available in the literature [28,29]. A linear thermal expansion coefficient of $8.1 \times 10^{-6}$ per ${ }^{\circ} \mathrm{C}$ was used for the concrete with Limestone aggregate based on the measurements by Ndon and Bergeson [28], while, a linear thermal expansion coefficient of $13.2 \times 10^{-6}$ per ${ }^{\circ} \mathrm{C}$ was used for the concrete with TG based on measured values given by the Building Research Board [29]. The modelling results obtained using the proposed thermal expansion coefficients were compared with that obtained using

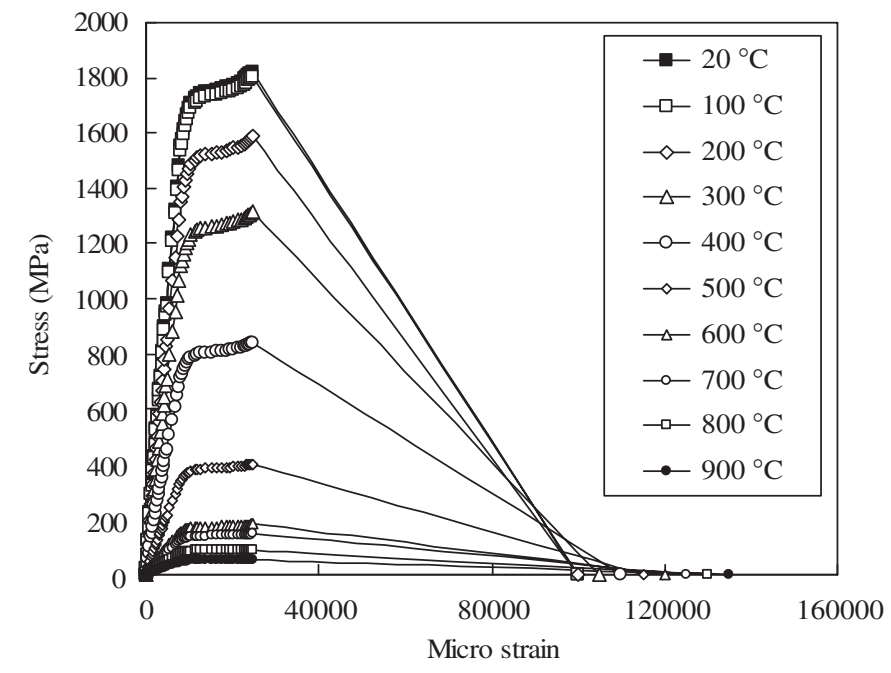

Fig. 5. Stress-strain curves of the tendon at elevated temperatures. 
the default thermal expansion coefficients given in BSEN1992-1-2 [20] for siliceous and calcareous aggregates.

Considering the observed behaviour of the restrained fire tests [8], it was found that the restraining beams did not provide full longitudinal restraint from the start of heating. It was found that the slab behaved similar to an equivalent unrestrained slab in the initial stages of the test until the bolts holding the restraining beams came into contact with edges of the holes. Once the initial movement took place, and the bolts started to bear against the holes, the slab became fully restrained. To highlight the significance of this initial movement, two different types of restraint conditions were adopted in the finite element model. The first is the assumption of an ideal horizontal rigid support. The second is the assumption of an initially free horizontal support up to a displacement of $4 \mathrm{~mm}$ followed by ideally rigid support, which represents the observations from the tests. The initially free support followed by an ideally rigid support has been denoted as 'initially free/rigid' support in this paper. The 'initially free/rigid' supports to the restrained slabs were applied using interface elements between the slab ends and the restraining beams, similar to those used between the tendons and grout. The interface elements allowed the initial thermal expansion $(4 \mathrm{~mm})$ and rotation of the slab observed in the tests [8] until the slab was in full contact with the restraining beams. The faces of the interface elements were the slab end (the slave surface) and a rigid plate representing the flange of the restraining beam (the master surface).

\section{Verification of the FE model}

At ambient temperature, the load-deflection behaviour, deformed shape at failure, stresses in the tendons and failure modes obtained from the finite element analysis were compared with the experimental results [21]. Generally good agreement was achieved. The failure load observed experimentally for Test T1 was $157 \mathrm{kN}$, at a central deflection of $82 \mathrm{~mm}$, compared to $160 \mathrm{kN}$ and $61 \mathrm{~mm}$ obtained from the model. The failure load predicted using the model was $2 \%$ higher than that observed from the Test T1. The failure load observed experimentally for Test T2 was $178 \mathrm{kN}$ at a central deflection of $94 \mathrm{~mm}$, compared with $185 \mathrm{kN}$ and $93 \mathrm{~mm}$ obtained from the model. The failure load predicted using the model was $4 \%$ higher than that observed in the Test T2. Further detailed comparison between the model and tests at ambient temperature can be obtained from Ref. [21], with this paper concentrating on the comparison with the four fire tests.

To indicate the accuracy of the thermal modelling the predicted temperatures at the hot surface (HS), the tendon (T), the mid-surface (MS) and the cold surface (CS) for Test T4 is shown in Fig. 6. Similar accuracy was obtained when the model was compared against the other fire tests.

The time-central deflection curves obtained from the tests and the finite element analysis were also compared, as shown in Figs. 7 and 8. In Fig. 7 the central deflection-time curves are plotted for Tests T3 and T5 using the measured thermal expansion coefficient $\left(K=8.1 \times 10^{-6}\right.$ per ${ }^{\circ} \mathrm{C}$ for concrete with Limestone and $13.2 \times 10^{-6}$ per ${ }^{\circ} \mathrm{C}$ for concrete with TG) and that presented in BSEN1992-1-2 [20] for normal weight concrete. For Test T3, the central deflection observed experimentally was $62 \mathrm{~mm}$ at $129 \mathrm{~min}$ from the start of heating, compared with $67 \mathrm{~mm}$ at $130 \mathrm{~min}$ and $76 \mathrm{~mm}$ at $112 \mathrm{~min}$ obtained from the model using the measured and the code thermal expansion coefficients (measured ' $K$ ' and EC ' $K$ ', shown in Fig. 7), respectively. Similarly the central deflection-time curves are plotted for the Test T5 in Fig. 7. The central deflection experimentally was $85 \mathrm{~mm}$ at $72 \mathrm{~min}$ from the start of heating, compared with $85 \mathrm{~mm}$ at $71 \mathrm{~min}$ and $115 \mathrm{~mm}$ at $43.5 \mathrm{~min}$ obtained

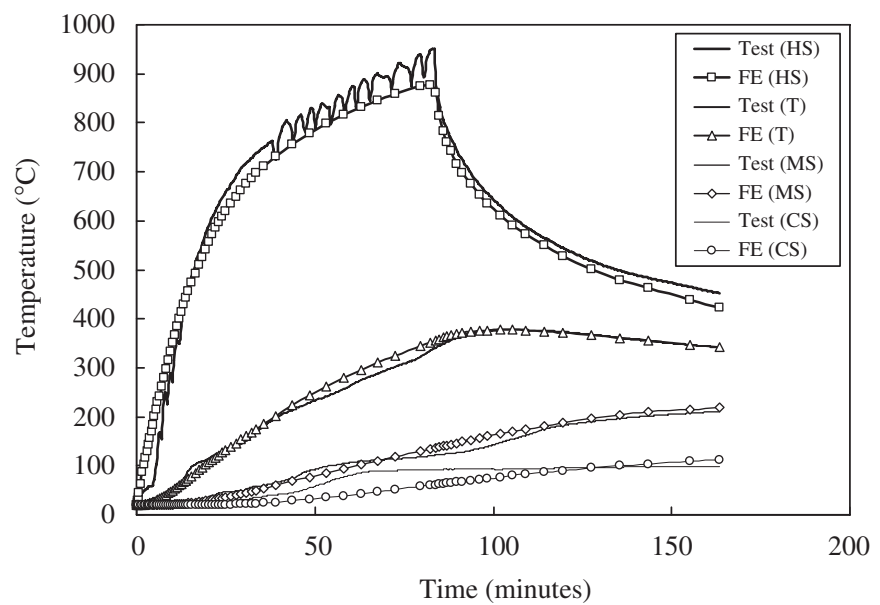

Fig. 6. Measured and predicted temperatures throughout the depth of the slab for Test T4.

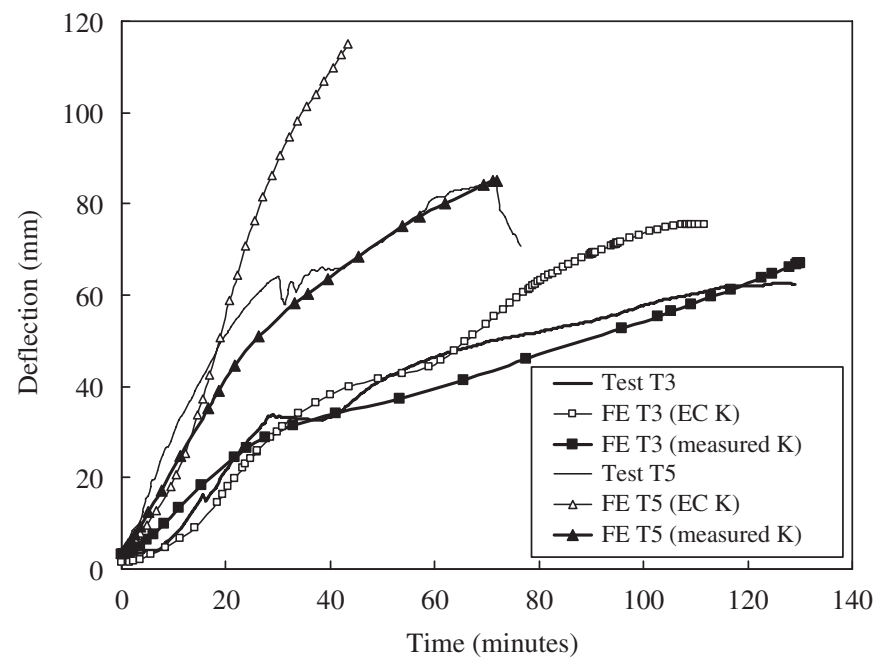

Fig. 7. Comparison between model predictions and tests results for Tests T3 and $\mathrm{T} 5$.

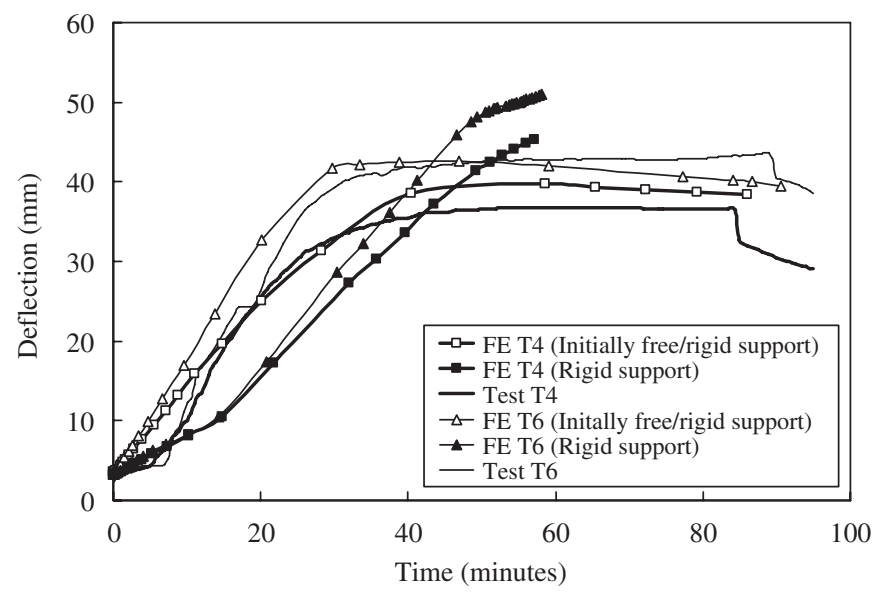

Fig. 8. Comparison between model predictions and tests results for Tests T4 and T6.

from the model using the measured and the code thermal expansion coefficients, respectively. Therefore as shown in Fig. 7 the time-deflection behaviour predicted from the model, using 
the EC code coefficients of thermal expansion, is inaccurate compared with that predicted using the measured thermal expansion coefficients given in $[28,29]$. Hence, the measured thermal expansion coefficients were used in simulating the remaining fire tests as well as carrying out the parametric studies to highlight the effect of restraint location and stiffness, load ratio and aggregate type.

Fig. 8 shows the central deflection-time curves plotted for the restrained fire Tests T4 (Limestone aggregate) and T6 (TG aggregate). In both cases the thermal expansion coefficient was based on measured data. The curves were plotted for the slabs restrained longitudinally by the ideally rigid and 'initially free/ rigid' supports previously discussed. For Test T4, the maximum central deflection observed experimentally was $37 \mathrm{~mm}$ at $58 \mathrm{~min}$ from the start of heating, compared with $45 \mathrm{~mm}$ at $57 \mathrm{~min}$ and $40 \mathrm{~mm}$ at $59 \mathrm{~min}$ from the model using ideally rigid and initially free/rigid' supports, respectively. For Test T6, the central maximum deflection observed experimentally was $43 \mathrm{~mm}$ at $62 \mathrm{~min}$ from the start of heating, compared with $51 \mathrm{~mm}$ at $58 \mathrm{~min}$ and $42 \mathrm{~mm}$ at $47 \mathrm{~min}$ from the model using rigid and initially free/ rigid' supports, respectively. In both tests it can be seen that the measured central deflections were initially higher than that predicted from the model using rigid supports due to the slab being allowed to expand slightly during the early stages of the test [8], whereas in the model the slab was fully restrained longitudinally from the start of heating. On the other hand, the 'initially free/rigid' supports were able to accurately model the restraint conditions in both tests. The modelling shows the importance of the horizontal restraint conditions and the effect of initial free movement followed by rigid restraint as observed in the tests.

Taking Test T4 as an example the deflected shape and stresses at the maximum temperature are shown in Fig. 9. Since Test T4 was restrained, the strains in the concrete elements at the restraint position approached the maximum compressive strains and hence, local concrete crushing was predicted using the finite element model, which compares well with the behaviour observed experimentally in the restrained tests [8]. Fig. 9 also shows that tensile stresses are concentrated at the tendon position and extend towards the top surface in the longitudinal direction of the slab.

The stresses in the tendons were predicted from the finite element analysis for all the slabs. The measured strains recorded by the strain gauges fitted on the tendons were used to predict the stresses in the tendons adopting the reduction factors given in the BSEN1992-1-2 [20]. As an example, the stresses predicted numerically were compared with those obtained experimentally for Test T5, as shown in Fig. 10. Generally good agreement was achieved between experimental and numerical results. It can be seen that the prestress force in the tendon started to decrease after $31 \mathrm{~min}$ in the test, compared with $26 \mathrm{~min}$ numerically. Similar behaviour was observed for the other tests.

The axial deformations for Tests T3 and T5 are also compared experimentally and numerically, as shown in Fig. 11. The maximum axial deformations were 6.2 and $10.5 \mathrm{~mm}$ at the midheight and top of the slab, respectively, recorded in the test, compared with 4.9 and $9.5 \mathrm{~mm}$ from the model.

One interesting observation from all the tests was the presence of longitudinal cracks directly above and inline with the tendons, as shown in Fig. 12. These cracks appeared between 15 and 21 min corresponding to a furnace temperature of between 738 and

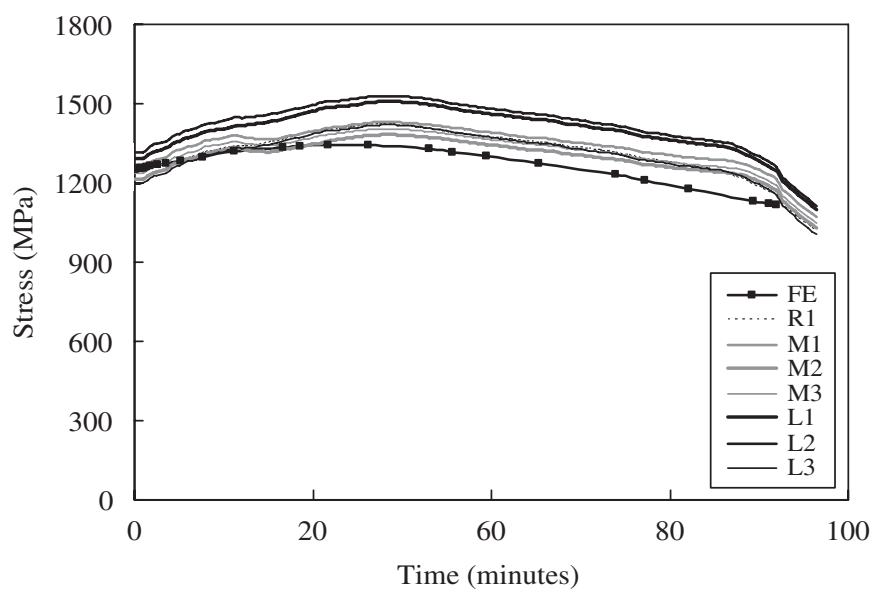

Fig. 10. Stress-time relationships on the tendons of the Test T5.

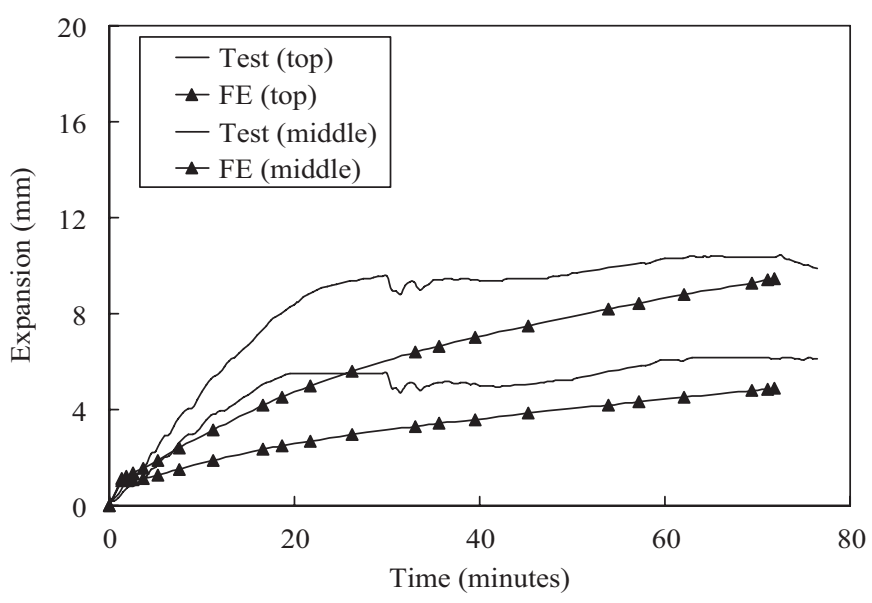

Fig. 11. Axial expansion-time relationship at the centreline of the movable edge of the Test T5.

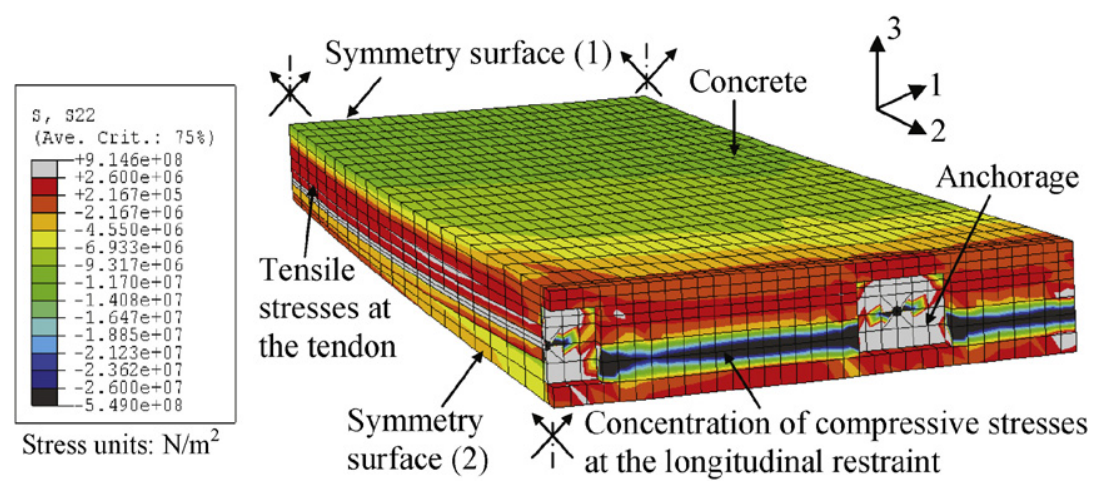

Fig. 9. Stress distribution in the concrete from the FE model for the Test T4. 
$786^{\circ} \mathrm{C}$, and a tendon temperature between 95 and $119^{\circ} \mathrm{C}$, depending on the slab tested. If we consider the modelling of Test 3 we can see that tensile stresses occurred above the tendons, as shown in Fig. 13. These cracks were not observed in the ambient tests or in the modelling of the ambient tests [21]. The cracks seem to be caused by tensile stresses being induced

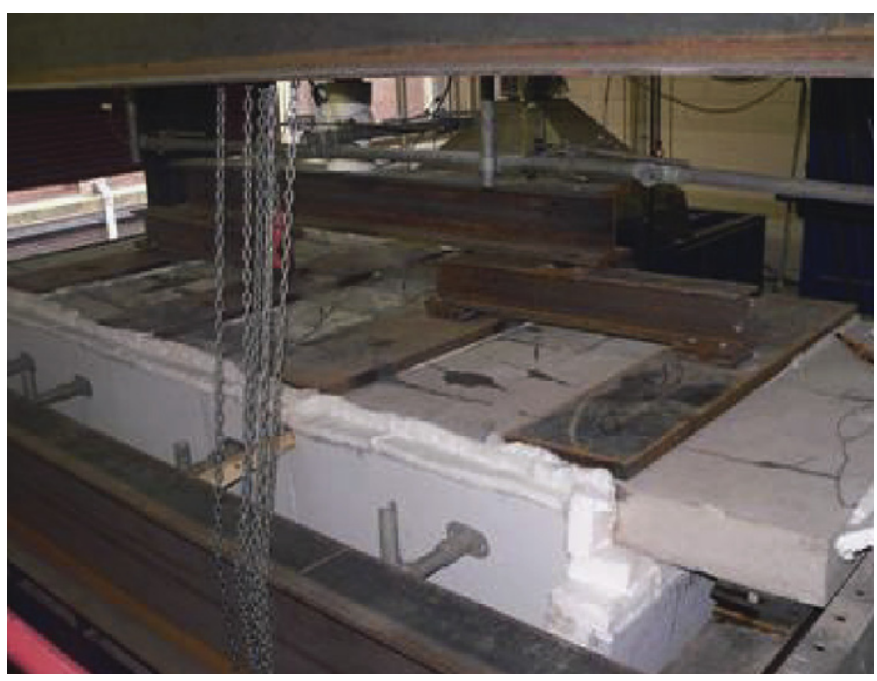

Fig. 12. Longitudinal cracks observed on the top surface of the fire Test $\mathrm{T} 3$. perpendicular to the trajectory of the tendons due to lateral thermal expansion at elevated temperatures. Initially, the lateral expansion is limited by the compressive stresses caused by the post-tensioning of the tendons. When the temperature of the tendons increases the tendon starts to expand longitudinally causing partial relief of the compressive stresses. The lateral expansion then subjects the cross-section of the slab to tensile stresses that causes splitting at the weaker section (the longitudinal section at the positions of the tendons). The same failure mode was also observed in independent tests conducted by Herberghen and Damme [3].

\section{Parametric studies and discussions}

The verified finite element model was used to investigate the effects of the change in the position of restraint over the slab's depth, axial restraint stiffness, load ratio and aggregate type on the global structural behaviour of unbonded post-tensioned oneway concrete slabs in fire. The different parameters are investigated and results are summarised in Table 3.

Group 1 (denoted G1) included three Slabs S1-S3 that were identical to that of Test T4 but analysed with different height positions for the line of longitudinal restraint (refer Table 3). The restraint position was taken at a height of $0.17 \mathrm{~h}, 0.34 \mathrm{~h}$ and $0.5 \mathrm{~h}$ from the bottom of the Slabs S1-S3, respectively, where $h$ is the overall depth of the slab. The longitudinal restraint was assumed to be ideally rigid along the width of the slab. The central

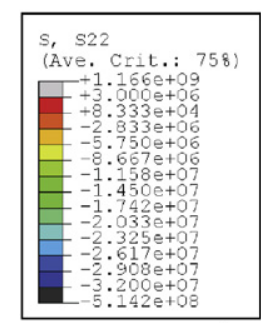

Stress units: $\mathrm{N} / \mathrm{m}^{2}$

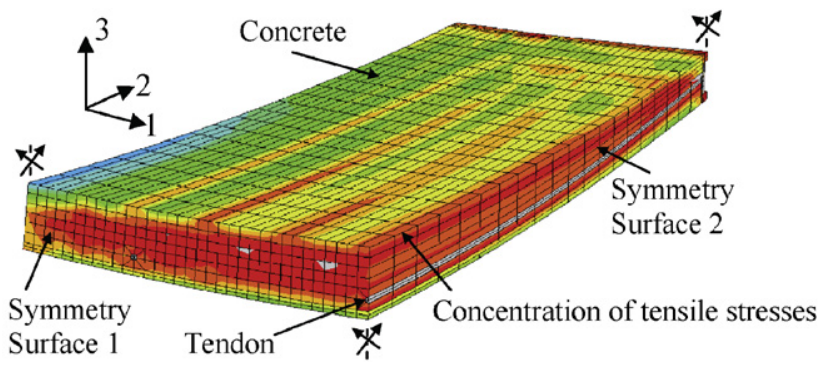

Fig. 13. Distribution of stresses in the concrete for the fire Test T3.

Table 3

Summary of parametric study results

\begin{tabular}{|c|c|c|c|c|c|c|c|c|c|}
\hline \multirow[t]{2}{*}{ Group } & \multirow[t]{2}{*}{ Test/slab } & \multirow[t]{2}{*}{ Agg. } & \multicolumn{3}{|l|}{ Parameter } & \multicolumn{2}{|l|}{ Present study } & \multirow{2}{*}{$\begin{array}{l}\text { BS } \\
\text { Fire res. (min) }\end{array}$} & \multirow{2}{*}{$\begin{array}{l}\text { EC } \\
\text { Fire res. (min) }\end{array}$} \\
\hline & & & Thrust position & Restraint stiffness & Load ratio & Max. def. (mm) & Fire res. (min) & & \\
\hline \multirow[t]{3}{*}{ G1 } & $\mathrm{S} 1$ & LS & $0.17 h$ & - & 0.65 & 6.0 & 31 & 90 & 60 \\
\hline & $\mathrm{S} 2$ & LS & $0.34 h$ & - & 0.65 & 45.3 & 57 & 90 & 60 \\
\hline & S3 & LS & $0.50 h$ & - & 0.65 & 81.0 & 85 & 90 & 60 \\
\hline \multirow[t]{7}{*}{ G2 } & S4 & LS & $0.34 h$ & Rigid & 0.65 & 45.3 & 57 & 90 & 60 \\
\hline & S5 & LS & $0.34 h$ & $100 \%$ & 0.65 & 44.0 & 54 & 90 & 60 \\
\hline & S6 & LS & $0.34 h$ & $10 \%$ & 0.65 & 52.0 & 61 & 90 & 60 \\
\hline & S7 & LS & $0.34 h$ & $7.5 \%$ & 0.65 & 55.0 & 64 & 90 & 60 \\
\hline & S8 & LS & $0.34 h$ & $1.0 \%$ & 0.65 & 73.3 & 86 & 90 & 60 \\
\hline & S9 & LS & $0.34 h$ & $0.1 \%$ & 0.65 & 80.6 & 85 & 90 & 60 \\
\hline & $\mathrm{S} 10$ & LS & - & Free & 0.65 & 81.0 & 85 & 90 & 60 \\
\hline \multirow[t]{3}{*}{ G3 } & S11 & LS & - & Free & 0.30 & 36.1 & 77 & 90 & 60 \\
\hline & $\mathrm{S} 12$ & LS & - & Free & 0.50 & 45.1 & 77 & 90 & 60 \\
\hline & $\mathrm{S} 13$ & LS & - & Free & 0.70 & 57.1 & 77 & 90 & 60 \\
\hline \multirow[t]{3}{*}{ G4 } & S14 & TG & - & Free & 0.30 & 63.4 & 72 & 90 & 60 \\
\hline & S15 & TG & - & Free & 0.50 & 73.0 & 71 & 90 & 60 \\
\hline & S16 & TG & - & Free & 0.70 & 88.9 & 71 & 90 & 60 \\
\hline
\end{tabular}


deflection-time relationships were plotted for Slabs S1-S3 as shown as in Fig. 14. It can be seen that the lower the restraint position the lower the overall vertical displacement of the slab. This is due to the thrust from the restraint position, as the slab tries to expand, creating a restraining moment at the ends, which reduces the central vertical displacement. The lower the line of thrust, the higher the restraining moment. The fire resistance period from the model ranged from 31 to $85 \mathrm{~min}$, showing clearly the significant effect of the position of the restraint to thermal expansion. Interestingly, although the vertical displacement was smaller as the position of restraint tended towards the bottom of the slab, the fire resistance period was also lower as shown in Table 3. This was due to localised failure in the proximity of the restraint being induced earlier as the restraint position tended towards the bottom of the slab. Similar to the tested slabs the tendon had a cover of $30 \mathrm{~mm}$ at the central span of the slab, which according to BS8110-2 [19], should achieve 90-min fire resistance. EN1992-1-2 [20] specifies fire resistance in terms of the distance from the bottom of the slab to the centre of the tendon (denoted axis distance), which, in this case, is $42 \mathrm{~mm}$. For 90 -min fire resistance EN1992-1-2 specifies an axis distance of $45 \mathrm{~mm}$ and for $60 \mathrm{~min}$ an axis distance of $35 \mathrm{~mm}$. Therefore the slab should have at least 60-min fire resistance (as shown in Table 3 ). However, the model shows that the codified values are only valid if the line of thrust from the resultant is at the mid-height of the slab. If the line of thrust is below the mid-height then the codified values are unconservative.

The effect of the magnitude of the restraint was investigated by modelling seven Slabs S4-S10 that were identical to that of Test T4 but had different axial restraint stiffness applied at a height of $0.34 \mathrm{~h}$ from the bottom of the slab. The group of slabs are denoted as G2 in Table 3 and had a stiffness ranging from ideally rigid, $100 \%, 10 \%, 7.5 \%, 1.0 \%$ and $0.1 \%$ of the slab axial stiffness at the ambient condition, and totally free to expand. Fig. 15 shows the central deflection-time relationships for the Slabs S4-S10, taking into account different restraint stiffness.

From Fig. 15, it can be seen that the Slab S6 with 100\% restraint stiffness behaved similar to the slab with ideally rigid supports. Slabs S7 and S8, having 10\% and 7.5\% restraint stiffness, behaved similar to the slab with rigid supports up to $50 \mathrm{~min}$ and then after had higher displacements. From Fig. 15 it can be seen that relatively moderate restraint stiffness ( $7.5 \%$ of the axial stiffness of the slab at ambient temperature) will give an initial response similar to an ideally rigid case. Slab S9, having a $0.1 \%$ axial restraint stiffness, behaved similar to a slab with totally free axial

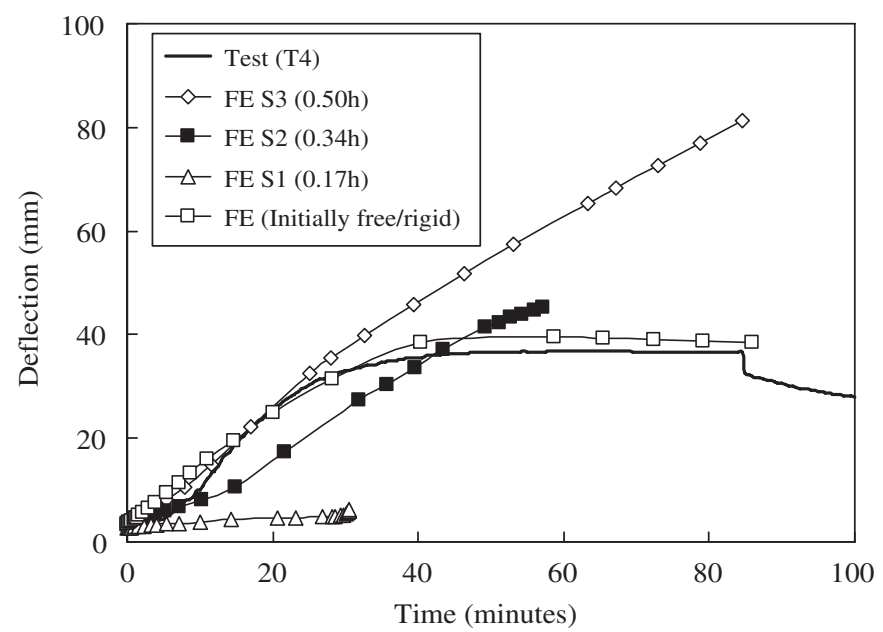

Fig. 14. Effect of line of thrust position on the central deflection-time relationship (Slabs S1-S3 of Group G1).

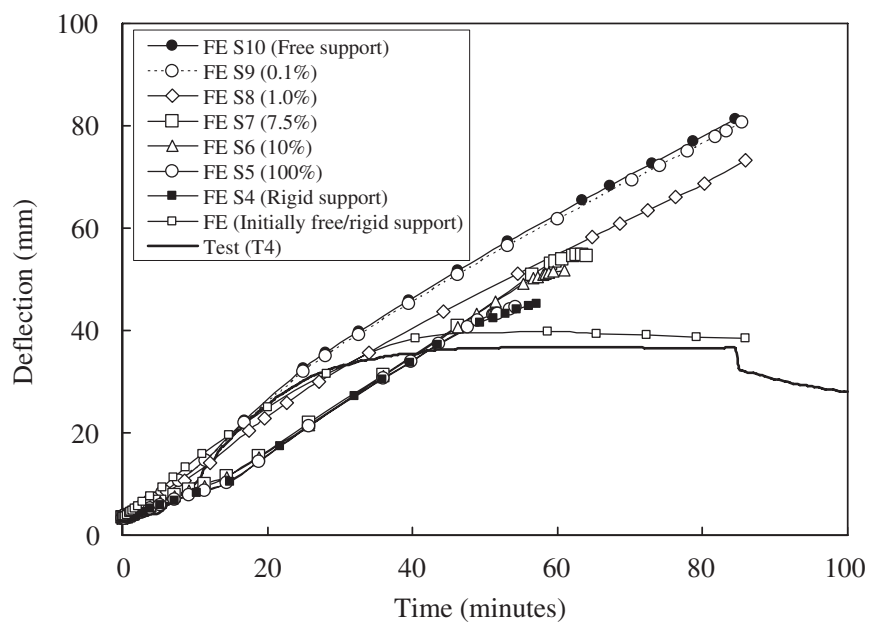

Fig. 15. Effect of axial restraint stiffness on the central deflection-time relationship (Slabs S4-S10 of Group G2).

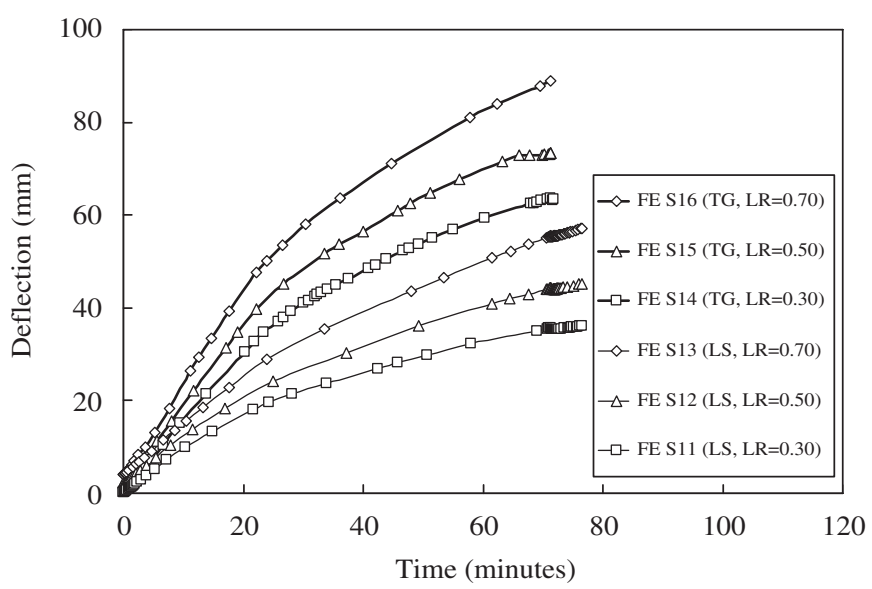

Fig. 16. Effect of load ratio and different aggregate types (LS=Limestone, TG $=$ Thames Gravel) (Slabs S11-S16 of Groups G3 and G4).

thermal expansion. The fire resistance from the model ranged from 57 to $85 \mathrm{~min}$, with the slab with free thermal expansion lasting longer. In this case the restraint was only provided to stop thermal expansion and the restraining springs did not allow catenary action within the slab to occur. Once again BS8110-2 [19] and EN1992-1-2 [20] suggest that these slabs should have a fire resistance period of 90 and $60 \mathrm{~min}$, respectively. The model shows that as the restraint increases the fire resistance period decreases and is unconservative compared to the code. Although if tying was included, and could be maintained for the duration of the fire, the predicted fire resistance period would increase.

The effect of the load ratio, defined as the applied load divided by the design capacity, was investigated by modelling the three Slabs S11-S13 in Group G3. The different load ratios were 0.3, 0.5 and 0.7 (Table 3). All the slabs in Group G3 were free to expand. From Fig. 16 it can be seen that the greater the load ratio the greater the vertical deflection of the slab for a given time. Of interest is the fact that all the slabs (S11-S13) failed at the same time ( $77 \mathrm{~min}$ ) irrespective of the load ratio. Previous experience has shown that the increase in the load ratio generally results in a decrease in the fire resistance. However, for the unbonded posttensioned concrete slabs investigated in this study, failure in the model was initiated due to a crack occurring directly inline and parallel to the tendons. As explained previously, when the temperature of the tendons increases the tendon starts to expand 
longitudinally, causing partial relief of the compressive stresses, which then allows the lateral expansion to cause splitting at the weaker sections of the slab. The same failure mode has also been observed in independent tests conducted by Herberghen and Damme [3]. From the study presented here it can be concluded that the splitting mode of failure is not affected by the applied static load. As shown in Table 3, Slabs S11-S13 failed at $77 \mathrm{~min}$, which is lower than the 90 min specified in BS8110-2 [19] and higher than the 60 min specified in EN1992-1-2 [20].

The parametric studies presented above used a constant thermal expansion coefficient of $8.1 \times 10^{-6}$ per ${ }^{\circ} \mathrm{C}$ relating to Limestone aggregate (LS). The last three Slabs S14-S16 in Group G4 were similar to those slabs in Group G3 but with a thermal expansion coefficient of $13.2 \times 10^{-6}$ per ${ }^{\circ} \mathrm{C}$ corresponding to a concrete with TG. As shown in Fig. 16 the slabs with TG aggregate have a significantly higher vertical deflection compared to the equivalent slab with Limestone, due to the greater thermal expansion of TG. Due to the variation of temperature through the depth of the slab, thermal curvature contributes to the vertical deflection (with the bottom part of the slab expanding greater than the top part), together will loss of strength of the tendon and concrete, with the TG slabs having the greater displacement. Once again the failure of the slabs occurred around $71 \mathrm{~min}$, as shown in Table 3. Similar to the slabs with Limestone gravel the failure was due to splitting, which was not influenced by the magnitude of applied static load. The analysis of Slabs S14-S16 (Table 3) showed that BS8110-2 [19] is unconservative and EN1992-1-2 [20] is conservative.

\section{Conclusions}

A nonlinear finite element model, for the analysis of unbonded post-tensioned concrete slabs at elevated temperatures, has been developed and presented. The interface between the tendon and surrounding concrete was modelled, allowing the tendon to retain its profile shape during the deformation of the slab. The temperature distribution throughout the slab, time-deflection behaviour, time-longitudinal expansion, time-stress behaviour of the tendon and the failure modes have been predicted by the model and verified against experimental results. The comparison between the experimental and numerical results has shown that the model can accurately predict the behaviour of unbonded posttensioned one-way concrete slabs under fire conditions.

The study has shown that the coefficients of thermal expansion currently used in EN1992-1-2 for calcareous and siliceous concrete are inaccurate. The values used in this study, based on measured values presented in the literature, have provided more accurate predictions for the structural behaviour of unbonded post-tensioned slabs. It has been also shown the model was efficiently able to predict the tensile stresses explaining the longitudinal cracking (splitting) observed above the tendons in all the tests.

The developed model was used to investigate the effects on the global structural behaviour due to the change in the aggregate type, load ratio and boundary conditions. It was shown that a relatively small restraining force $(7.5 \%$ of the axial stiffness of the slab) is required to obtain a similar displacement-time response compared to a fully restrained slab. It is also shown that the central deflection is increased with the increase of the load ratio but the fire resistance time remains the same, due to the mode of failure comprising cracking (splitting) above the tendons not being influenced by the magnitude of load. Similarly, using different aggregates influenced the displacement-time response but did not significantly affect the failure fire resistance time. The numerical results were compared with values calculated using current design codes. The comparison has shown that the slabs generally had fire resistances less than that specified in the British Standard BS8110, with the European Code EN1992-1-2 producing reasonable design values.

\section{Acknowledgements}

The work in this paper was conducted at the University of Manchester and was funded by EPSRC (Grant no. EP/D034477/1). The authors are grateful to Tarmac Ltd. for supplying the concrete, Bridon Ltd. for supplying the tendons, and CCL Ltd. for supplying the dead and live anchorages. The authors are also grateful to $\mathrm{Mr}$ Paul Nedwell, for his continuous support and useful discussions and the support provided by the technical staff at The University of Manchester, headed by Mr Paul Townsend and Mr Jim Gee.

\section{References}

[1] U. Laboratories, PCI J. (1968) 45-56.

[2] A.H. Gustaferro, PCI J. (1973) 38-63.

[3] P.V. Herberghen, M.V. Damme, J. Fédération Int. de la Précontrainte (1983/ 1984) 3-11.

[4] P. Lukkunaprasit, Unbonded post-tensioned concrete flat plates under 5 hours of fire, in: FIP-XIth International Congress on Prestressed Concrete, S61-S64, Hamburg, Germany, 1990, pp. 4-9.

[5] G.E. Troxell, ASCE (1965) 64-66.

[6] D. Sarkkinen, Struct. Forensics (2006) 32-34.

[7] D.Y.C. Lee, C.G. Bailey, The behaviour of post-tensioned floor slabs under fire conditions, in: International Technical Congress, Fire Safety in Tall Buildings, Universidad de Cantabria, Santander, Spain, 2006, pp. 183-201.

[8] C.G. Bailey, E. Ellobody, Fire tests on unbonded post-tensioned concrete slabs, Mag. Concr. Res. 60 (2008) in press.

[9] D. Hosser, T. Dorn, O. El-Nesr, J. Struct. Eng. ASCE 120 (10) (1994) 2871-2892.

[10] C.G. Bailey, I.W. Burgess, R.J. Plank, Struct. Eng. 74 (6) (1996) 93-100.

[11] B.A. Izzuddin, J. Eng. Mech. ASCE 122 (9) (1997) 861-871.

[12] L. Song, B.A. Izzuddin, A.S. Elnashai, P.J. Dowling, J. Constr. Steel Res. 53 (2000) 63-85.

[13] A.Y. Elghazouli, B.A. Izzuddin, Fire Saf. J. 36 (2001) 769-793.

[14] M. Gillie, A. Usmani, M. Rotter, M.O. Connor, Fire Saf. J. 36 (2001) 745-767.

[15] L. Lim, A. Buchanan, P. Moss, J.M. Franssen, Eng. Struct. 26 (2004) 1081-1091.

[16] Y.X. Zhang, M.A. Bradford, Nonlinear analysis of moderately thick reinforced concrete slabs at elevated temperatures using a rectangular layered plate element with Timoshenko beam functions, Eng. Struct. 29 (10) (2007) 2751-2761.

[17] E. Ellobody, C.G. Bailey, Experimental and Numerical Investigation of PostTensioned Unbonded Concrete Slabs In Fire, Interflam 2007, vol. 3-5, Interscience Communications Ltd., London University, Royal Holloway College, London, 2007, pp.617-628.

[18] ABAQUS Standard/Explicit User's Manual. Hibbit, Karlsson and Sorensen, Inc. $1-3$, Version 6.5-4, USA, 2006.

[19] BS 8110-2, Structural use of concrete, Code of Practice for Special Circumstances, British Standards Institution, London, 1985.

[20] Eurocode 2. Design of concrete structures, General rules, Structural fire design (together with United Kingdom National Application Document), British Standards Institution, BSEN 1992-1-2, London, 1992.

[21] E. Ellobody, C.G. Bailey, Adv. Struct. Eng. 11 (1) (2008) 107-120.

[22] BS 8110-1, Structural use of concrete, Code of Practice for Design and Construction, British Standards Institution, London, 1997.

[23] Technical Report 43, Post-Tensioned Concrete Floors: Design Handbook, Concrete Society, Surrey, UK, 2005.

[24] Eurocode 1, Actions on structures. General Actions. Actions on Structures Exposed to Fire. British Standards Institution, BSEN 1991-1-2, London, 2002.

[25] CEB. RC Elements under cyclic loading. Comite Euro-International Du Beton (CEB), Thomas Telford, 1996.

[26] BS 4447, Specification for the Performance of Prestressing Anchorages for Post-Tensioned Construction, British Standards Institution, London, 1999.

[27] D.Y.C. Lee, C.G. Bailey, The behaviour of post-tensioned floor slabs under fire conditions, in: SEMC 2007, The Third International Conference on Structural Engineering, Mechanics and Computation, University of Cape Town, South Africa, 2007, pp. 1253-1257.

[28] U.J. Ndon, K.L. Bergeson, J. Mater. Civil Eng. ASCE 7 (4) (1995) 246-251.

[29] Building Research Board. The thermal expansion of concrete. National Building Studies, Technical paper, No. 7 HMSO, 1950. 